\title{
There are more thinhgs. El horror lovecraftniano en la obra de Jorge Luis Borges ${ }^{1}$
}

Jaime Romero Leo ${ }^{2}$

Resumen. El siguiente artículo investiga acerca de la contradictoria relación que Jorge Luis Borges mantuvo con la obra de H. P. Lovecraft. A través del cuento There are more things se analizarán los rasgos literarios del escritor argentino, a la vez que se demostrará como conoció de primera mano la obra de Lovecraft hasta el punto de llegar a realizar una simbiosis entre la mitología del escritor norteamericano y la suya propia. Dichos planteamiento serán desarrollados en torno a la categoría del horror lovecraftiano, el cual será ironizado por Borges.

Palabras clave: Lovecraft; Borges; Romanticismo; horror; sublime; mitología; estética.

\section{[en] There are more thinhgs. The Lovecraftnian horror in the work of Jorge Luis Borges}

\begin{abstract}
This article considers the contradictory relationship that Luis Borges had with the work of H. P. Lovecraft. For this reason, the literary features of the argentinian writer will be analyzed through his there are more things tale and it will be proved how he first-hand met the work of Lovecraft to the point that he made a simbiosis of the American writer mythology and his owns. These approaches will be developed on the lovecraftian horror category, which will be ironically treated by Borges.
\end{abstract}

Keywords: Lovecraft; Borges; Romanticism; horror; sublime; mithology; aesthetics.

Sumario. 1. El Romanticismo oscuro a través de una perspectiva hispanoamericana. 1.1. La pesadilla como fuente de inspiración literaria. 2. El sueño de la razón como metáfora de la creación literaria lovecraftniana. 3. La confrontación entre la categoría estética de lo sublime y el horro lovecraftniano. 3.1. Mitología. 3.2. El horror en relación a la deidad. 3.3. Entre el horror y lo sublime.

Cómo citar: Romero Leo, J. (2019) The are more thinhgs. El horror lovecraftniano en la obra de Jorge Luis Borges, en Anales de Literatura Hispanoamericana 48, 473-484.

\footnotetext{
1 Este artículo se integra entre los resultados del Grupo de Investigación Reconocido en Estética y Teoría de las Artes (Universidad de Salamanca, Instituto de Iberoamérica)

2 Universidad de Salamanca, Salamanca. España.

E-mail: jaimeromeroleo@usal.es
} 


\section{El Romanticismo oscuro a través de una perspectiva hispanoamericana}

Hablar del Romanticismo implica hacerlo inevitablemente de las influencias trazadas a lo largo de los siglos XIX y XX hasta nuestros días. Sus ecos resuenan aún con fuerza en el cine, la literatura, la publicidad o la música del presente, al cual algunos han definido como época "postromántica" (Molinuevo, 2009: 51-52). Ello se debe en gran parte a la recepción e impulso que, a principios de siglo pasado, autores punteros del género le otorgaron.

Si dentro de la amplia gama de corrientes y propuestas que emanaron de los diferentes países europeos, se centra la atención en las ofrecidas por el Romanticismo angloamericano en particular, se observa que su influencia es fácilmente rastreable a lo largo de Europa, Estados Unidos y parte de Asia. El mapa de influencias nos lanza a la pregunta por Latinoamérica, y nada mejor que escoger a una de las figuras referentes de la literatura contemporánea en habla hispana como lo fue Jorge Luis Borges para responderla. En esta ocasión no se realizará el acercamiento desde su relación con la obra de Poe, autor por el que el argentino sintió gran admiración (Borges, 1949: 1), sino desde uno de sus principales receptores y contemporáneo del mismo Borges: H.P. Lovecraft. ${ }^{3}$

La obra There are more things recogida en El libro de arena, publicado póstumamente en 1975, contiene en el epílogo una contradictoria referencia de Borges a la obra de Lovecraft. En ella, el argentino define al norteamericano como un "parodista de Poe" (Borges, 2011a: 5). Lo hace a la vez que demuestra un conocimiento soberbio de su obra, hasta el punto de decidirse a escribir un relato de estructura eminentemente lovecraftiana; manera en la que, según algunos teóricos y allegados al propio Borges como Alberto Manguel, intentó desasirse de ese dilema que le causaba la figura del escritor norteamericano. De esta manera, el relato plantea una simbiosis entre la simbología borgiana y la lovefcratiana desde la que puede llevarse a cabo análisis, en clave hispanoamericana, de ciertas influencias románticas que impregnaron al relato de terror de Borges.

Tal y como refiere Rafael Llopis en su introducción a Los mitos de Cthulhu, la importancia de Lovecraft estribó en que fue capaz de renovar el género al utilizar un terror arcaico y primitivo con el que "golpear" al entrenado lector del cuento de miedo gótico, al cual costaba cada vez más aterrorizar con los recursos usuales (Llopis, 2012: 37-38). Categorías estéticas como la de lo "sublime", definido por Edmun Burke como esa "especie de horror delicioso" (Burke, 2014: 29), se tornaron un horror insalvable, impronunciable e indescriptible, al que la curiosidad de Borges decidió asomarse con los ojos abiertos. De este modo, la relación que se establecerá en el siguiente artículo entre Borges y Lovecraft a través del relato There are more things se realizará mediante el análisis de tres planteamientos encadenados entre sí: la "pesadilla" como inspiración, el sueño de la razón como metáfora de la creación literaria lovecraftiana y la confrontación entre la categoría

\footnotetext{
${ }^{3}$ Las premisas desde las que dicha comparación serán elucidadas se resumen en los tres aspectos que el profesor Francisco José Francisco Carrera ha defendido a la hora de establecer una posible relación entre Borges y Lovecraft: " 1 ' la constatación de un número significativo de motivos comunes que aparecen en los relatos de ambos autores, $2^{\circ}$ la certeza de que Borges conocía la obra del autor norteamericano y $3^{\circ}$ la existencia (...) de ciertos estudios comparativos en la literatura" (Francisco Carrera, 1999: 7-8). En éste tercer grupo cabría insertar el propio artículo de Francisco Carrera.
} 
estética de lo sublime y el horror lovecraftiano. Los dos primeros servirán de nexo para el tercero y más extenso de los puntos aquí planteados, en donde se abordará la imposibilidad de goce o disfrute estético de la categoría del horror lovecraftiano.

\subsection{La pesadilla como fuente de inspiración literaria}

A pesar de la contradictoria relación que Borges mantuvo con la obra del escritor norteamericano, es indudable el hecho de que, ya fuese apreciándolo en algunas ocasiones (Borges, 1999: 122-123) o minusvalorándolos en otras (Borges, 2011: 5), Borges tuvo un profundo conocimiento acerca de los relatos póstumos de H. P. Lovecraft, que el llamado "Círculo de Lovecraft" publicó tras la muerte del autor (Llopis, 2012, 25-26). Muestra de ello, es que el relato que el argentino decidió dedicarle sentó sus bases en la misma fuente de inspiración de la que el escritor norteamericano se sirvió a lo largo de su vida para crear sus historias: la pesadilla. Al igual que para Lovecraft, las pesadillas recurrentes del argentino se convirtieron en una obsesión literaria, llegando toda su obra a referir de una manera más o menos indirecta a los mismo temas cumbre: las máscaras, el espejo, el tiempo... ("Jorge Luis Borges: Siete noches. La pesadilla." YouTube. YouTube, LLC, 9 Junio 2013. Web. 7 Abril 2016).

En There are more things Borges trae a colación la pesadilla del laberinto como eje de su relato. Su protagonista aventura: "Aquella noche no dormí. Hacia el alba soñé con un grabado a la manera de Piranesi" (Borges, 2006 p. 63). Las connotaciones angustiosas de la opresora sensación que producen los grabados de Giovanni Battista Piranesi serán perfectas para recrear la pesadilla lovecraftiana ${ }^{4}$. (Fig. 1).

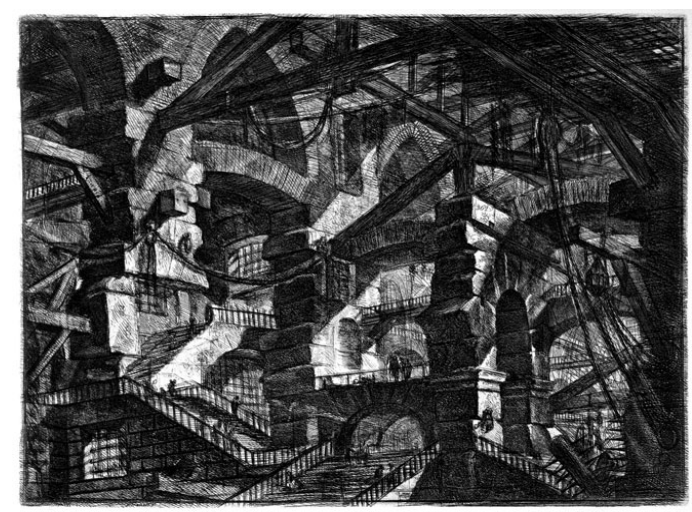

Figura 1. Giovanni Battista Piranesi, Cárcel d'Invenzzione, 1745-1760.

Respecto al grabado, el protagonista explica que le recuerda a: "Un lugar que nunca había visto o que había visto y olvidado" (Borges, 2006 p. 63). Una

\footnotetext{
${ }^{4}$ Una de las colecciones más famosas de Giovanni Battista Piranesi fue la de Carceri d'Incenzione, creada entre 1745 y 1760. En ésta, Piranesi transformó las ruinas romanas en fantásticos y desproporcionados calabozos, en donde interminables e incongruentes pasadizos, escaleras, cuestas y galerías se entrelazaban entre sí de un modo totalmente irracional. La influencia de estos grabados es palpable en el Romanticismo así como en el desarrollo durante el siglo XX de corrientes como el surrealismo.
} 
descripción que se ciñe a lo que representa precisamente esa ruina "remodelada" de Piranesi. Los salones que aparecen representados recuerdan a la Roma antigua de la que provienen, pero lo que aquí acontece es otra cosa: un nuevo universo elaborado con los pedazos de otro más antiguo. Afirmación clave ésta con la que podría describirse en líneas generales a toda la obra de Lovecraft (Llopis, 2012: 37). Aquel laberinto surgió en los sueños del protagonista de Borges tras la desconcertante conversación que mantuvo con el arquitecto de la mansión que había adquirido el forastero Max Preetorius. Según el arquitecto le explicó, Preetorius le pidió que llevase a cabo una extraña remodelación en su interior. En aquellos extraños sueños sobre siniestros laberintos, el protagonista se encontraría nada más y nada menos que con un minotauro apaciblemente dormido ${ }^{5}$. Lo describe de la siguiente manera: "El monstruo de un monstruo. Tendido en la tierra parecía dormir y soñar. ¿Soñar con qué, con quién?”. El sueño de la razón produce monstruos, parece traer a colación esta escena; algo que, Lovecraft, tras la primera crisis nerviosa que sufrió a los 18 años y a la que le seguirían otras cada vez más agudas hasta el día de su muerte, experimentó de primera mano ${ }^{6}$.

\section{El sueño de la razón como metáfora de la creación literaria lovecraftniana}

Borges ya había advertido la dinámica que el título que Goya confirió a su grabado en 1799 (Fig. 2). Lo demostró en Las ruinas circulares, publicado en 1940 en la revista Sur, otro relato en donde pueden hallarse algunos otros vestigios del romanticismo inglés a parte del terror post-gótico que protagoniza There are more things.

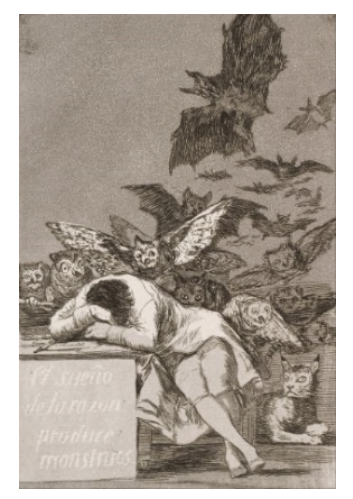

Figura 2. Francisco de Goya, El sueño de la Razón produce monstruos, 1799.

\footnotetext{
${ }^{5}$ El Minotauro es una de las figuras más reconocibles de la imaginería borgiana, siendo recuerrente en diversos relatos como el de La casa de Asterión, recogido en El Aleph en 1949.

${ }^{6}$ Tras la primera crisis nerviosa Lovecraft abandonó la escuela secundaria y se recluyó hasta los 24 años en el caserón familiar. El mito del escritor recluido en su mansión, despierto solo durante la noche y escribiendo por el día con las persianas de su habitación bajadas para conservar el ambiente de penumbra, comenzó a forjarse ya durante esta primera etapa. Para un análisis sobre algunos de los episodios más representativos de la vida de Lovecraft y de cómo influirían más tarde a lo largo de su obra véase: Hernández de la Fuente, David, Lovecraft. Una mitología, Madrid, Luis Revenga, 2005.
} 
En Las ruinas circulares puede advertirse la temática de la denominada "Creación artificial" o "Segundas Creaciones" que tanto se popularizó a lo largo del gótico inglés (Molinuevo, 2004: 112-113) y que, años más tarde, sería recuperado por los escritores del cuento de terror americano como Lovecraft (Lovecraft, 2017: 64-65), con algunas variantes interesantes (Hernández de la Fuente, 2005: 55). En Las ruinas circulares Borges presentaba a un ser que, desde su sueño, creaba a otro individuo con la única misión de partir río abajo para, desde su sueño, crear a otro. Es entonces, una vez realizada la empresa de navegar río abajo, encontrar una orilla y "soñar", cuando el protagonista se da cuenta de su condición de "criatura" y de cómo su antecesor, aquel que soñándolo le había otorgado la vida, había borrado cualquier resquicio de recuerdo anterior durante el proceso de creación.

Lovecraft recuerda en cierta forma a la singular criatura borgesiana. El escritor norteamericano es por antonomasia el "creador" de sueños y fantasías que envolverían a la literatura tardogótica norteamericana. Creador de sueños o, más bien, de pesadillas, como se ha referido. De pesadillas que, al igual que en el relato de Las ruinas circulares, provinieron de un mundo de miedo y pavor previo en el que el joven Lovecraft fue criado y en el que construyó su personalidad. Un mundo marcado por el temor a los otros, a la enfermedad, al mundo exterior que una sobreprotectora madre y una figura paterna inexistente estimularon desde niño (Llopis, 2012: 20-34). Las lecturas que la biblioteca familiar le proporcionó en torno a las grandes civilizaciones que poblaron el mundo así como de sus extraños rituales, una infancia de reclusión, una personalidad retraída, su amor por la astronomía y los misterios del universo, crisis nerviosas, la noche como inspiración, su pasión declarada por los relatos de Poe... (Lovecraft, 2017: 87-97) Todo ello supuso el caldo de cultivo que germinaría en la prolífica producción literaria que el norteamericano dejó, a pesar de su prematura muerte a los cuarenta y seis años.

Lovecraft comprendió mejor que nadie la máxima goyesca referida de que "El sueño de la razón produce monstruos". Era por ello que escribía cuando el mundo dormía, por la noche, o si era por el día, lo hacía con las persianas bajadas. Dando rienda suelta a los miedos que le atormentaron a lo largo de su vida y expresándolos a través de su literatura, desde la cual engendró todo un universo abrumador y perverso para el ser humano. Conceptos tan importantes en la obra de Lovecraft como lo son la pesadilla, el sueño y el insomnio como forma de escape de los terrores innombrables que la noche traía consigo, quedaron reflejados en relatos como Hipnos, publicado en 1923 en la revista National Amateur. Precisamente, el relato se abre con una cita de Baudelaire que pone en situación al lector: "A propósito del sueño, esa siniestra aventura de todas nuestras noches, podríamos decir que los hombres se acuestan diariamente con una osadía incomprensible, si no supiéramos que es a causa de la ignorancia del peligro". A través de sus relatos, el nortemaericano dio rostro a sus angustias más profundas. Éstas estuvieron teñidas de un tipo de horror muy concreto derivado de la evolución histórica que desde los relatos góticos había acontecido hasta llegar a su tiempo. Denominó a este horror "terror cósmico". Según el propio Lovecraft expuso en su ensayo El terror en la literatura, se trataba éste de una de las cúspides a las que el relato de terror había llegado. A partir de ello, cabe preguntar 
cuáles son las formas que aquella desdichada angustia cobró en sus relatos, es decir, cuál es el rostro que tiene un horror impronunciable como lo es aquel "terror cósmico". Y, quizá lo que más pavor dio al propio Lovecraft, cuando nos encontramos ante tal horror, qué cabe esperar de nosotros.

\section{La confrontación entre la categoría estética de lo sublime y el horro lovecraftniano}

Se acerca el fin. Oigo ruido en la puerta, como si forcejeara en ella un cuerpo inmenso y resbaladizo. No me encontrará.

¡Dios mío, esa mano! ¡La ventana! ¡La ventana! Dagón, de H. P. Lovecraft

He aquí el punto en donde se encuentra la principal ruptura que Borges plantea con la literatura de Lovecraft. There are more things sigue la misma estructura narrativa a la que Lovecraft se adhiere. Llegando al final del relato, Borges afianzará aún más dicha relación estructural al describir el interior de la mansión reformada por Preetorious en los mismos términos estéticos en los que lo hace el escritor norteamericano. A pesar de ello, inesperadamente, en la última línea del cuento, el argentino decide dar un giro argumental que lo distanciará radicalmente del final del cuento de terror lovecraftiano y que, una vez más, pondrá de manifiesto la cercanía que mantuvo con la obra de Lovecraft. Desde los puntos trazados a lo largo del artículo se ha puesto de manifiesto como Borges está familiarizado con la forma de escribir de Lovecraft. En este apartado final, se descubre que lo está hasta el punto de ironizar sobre el horror y la forma de afrontarlo por parte de sus personajes.

Cuando el protagonista pide información sobre la mansión al carpintero que Preetorius finalmente contrató para llevar a cabo la remodelación del interior de la vivienda, éste no deja claro en qué consistió exactamente su labor, pero sí que no volverá a poner un pie en aquella casa y que Pretrorius está loco. La misma descripción llevada a cabo por Lovecraft de aquello que es indescriptible es expresada de forma magistral por Borges. No se trata de mostrar tanto lo que se ve como lo que produce verlo (Aparicio Maudeu, 2010: 11-12). Se trata pues de una descripción sentimental más que material, lo suficientemente general como para que el mismo lector rellene con sus propios temores los huecos que deja la narración (Joannon, 1999: 79).

El comedor y la biblioteca de mis recuerdos eran ahora, derribada la pared divisoria, una sola gran pieza desmantelada, con uno que otro mueble. No trataré de describirlos, porque no estoy seguro de haberlos visto, pese a la despiadada luz blanca. Me explicaré. Para ver una cosa hay que comprenderla [...]. Ninguna de las formas insensatas que esa noche me deparó correspondía a la figura humana o a un uso concebible. Sentí repulsión y terror [...] Ya arriba mi temerosa mano hizo girar por segunda vez la llave de la luz. La pesadilla que prefiguraba el piso inferior se agitaba y florecía en el último. (Borges, 2011b: 6667) 
Llegados a este punto del relato, la descripción continúa con las relaciones extraídas directamente del universo simbólico de Lovecraft. Borges lo hace a través de tres referencias que se tornan clave en toda la obra del norteamericano: la mitología, el horror como deidad y la referencia al terror cósmico o extraterrenal.

\subsection{Mitología}

Había muchos objetos o unos pocos objetos entretejidos. Recupero ahora una suerte de larga mesa operatoria, muy alta, en forma de U, con hoyos circulares en los extremos [...]. De alguna página de Lucano, leída hace años y olvidad, vino a mi boca la palabra Anfisbena, que sugería, pero no agotaba por cierto lo que verían luego mis ojos. (Borges, 2011b: 67)

Es sabido que Lovecraft conoció el entramado mitológico de numerosas civilizaciones desde una edad temprana como ya se ha comentado; lo interesante de su obra es que, a través de ella, y asumiendo las influencias literarias de su juventud, logró crear su propio panteón. Autores como el citado Francisco Carrera han destacado este interés por lo mitológico como uno de los nexos más evidentes que pueden establecerse entre ambos autores (Francisco Carrera, 1999: 15). Es por ello que no resulta extraño que en un texto como There are more things Borges recurra precisamente a un ser mitológico recogido en su bestiario, ayudando a alimentar el entramado mítico-religioso al que acostumbran los mundos de pesadilla del escritor norteamericano. El ser (la Anfisbema) corresponde a un mito griego de la antigüedad, civilización con la que Lovecraft se sintió profundamente unido tal y como explicamos líneas más arriba. Borges sabe que si las pesadillas son la primera fuente de inspiración del norteamericano, la mitología es la segunda; al igual que ocurre precisamente en su propia obra (Francisco Carrera, 1999: 1516).

\subsection{EI horror en relación a la deidad}

Pensé que podía ser el lecho del habitante, cuya monstruosa anatomía se revelaba así, oblicuamente, como la de un animal o un dios. (Borges, 2011b: 68)

Lovecraft es conocido por haber dado lugar a una teogonía entera que sus sucesores, (sobre todo August Derleth) se encargaron de sistematizar. El mundo onírico que creó, y que sus allegados ayudaron a nutrir, ha sido fuente de inspiración de numerosas personalidades en el ámbito de la literatura, el cine, el videojuego y el cómic.

Los miedos primarios e innombrables fueron personificados en los indescriptibles "Dioses Primordiales". Estos fueron desterrados o encarcelados por los "Dioses Arquetípicos" durante un período muy anterior al de la aparición de los seres humanos según nos descifran los textos de Lovecraft. Sus historias giran, precisamente, sobre estas deidades y sobre los contactos, más o menos directos, que los protagonistas de sus relatos mantendrán con ellas. Con los adormecidos y encarcelados dioses primordiales a los que, los desafortunados, tendrán el "privilegio" de conocer. 


\subsection{Entr el horror y lo sublime}

¿Cómo sería el habitante? ¿Qué podía buscar en este planeta, no menos atroz para él que él para nosotros? ¿Desde qué secretas regiones de la astronomía o del tiempo, desde qué antiguo y ahora incalculable crepúsculo, habría alcanzado este arrabal sudamericano y esta precisa noche? (Borges, 2011b: 68)

Los miedos de Lovecraft siempre vienen de fuera, del exterior o del interior más recóndito, pero no pertenecen a nuestra geografía mundana y conocida. No es casualidad que se recuerde a Lovecraft como un segregacionista empedernido según han apuntado autores como Houellebecq (Houellebecq, 2006: 25-31). El terror procede de un profundo agujero en la tierra, de los fondos marinos a los que el hombre aún no ha llegado, del espacio exterior o de dimensiones distintas a la nuestra. En cualquiera de los casos se pone de manifiesto la impotencia del ser humano para enfrentarse o siquiera comprender aquello con lo que se enfrenta. Estas tres referencias trazadas de forma magistral por Borges en apenas una página confluyen a lo largo de toda la obra de Lovecraft a través de un denominador común: "el horror", la grandeza descomunal que lo mitológico-divino proyecta y que el ser humano no es capaz de englobar en su mente finita. La descripción parece apuntar hacia la categoría de lo "sublime" que diversos autores trataron en torno al siglo XVIII y XIX y a los distintos tipos en los que la sublimidad se manifestó (HERNÁNDEZ, 2009: 11). Entre ellos destaca la figura de Burke y la citada relación que estableció entre lo sublime y el placer estético que desencadena un horror delicioso.

A pesar de que en el artículo se pone el énfasis en la categoría estética de lo sublime entendida a la manera de Burke, cabe matizar que otras interpretaciones desde otros ámbitos estéticos son posibles. Especial mención referiría, por ejemplo, lo "siniestro", entendido desde una perspectiva freudiana. Según Freud, lo siniestro se produce cuando lo "extraño" emana de lo apacible y cotidiano; aquello que denominó Unheimlich. Como ha apuntado Joannon, precisamente esa apacibilidad sería uno de los primeros quiebros que se darían al representar la casa paterna despojada en el presente de toda calidez:

Pienso que es conveniente considerar la Casa Colorada como un entorno familiar, que súbitamente se ve violentado, sin mayor explicación, por una extrañeza inefable. Lo familiar se vuelve ajeno y ante eso se está indefenso; no hay cómo protegerse ante tal embestida. (Joannon, 1999: 74)

Precisamente, ese interés por lo siniestro se vuelve otro de los nexos de unión entre el escritor norteamericano y el argentino tal y como expone Francisco Carrera:

Cuando lo extraño se vuelve familiar o lo cotidiano extrañamente ajeno, es entonces cuando penetramos en los mundos posibles e imposibles que tantas veces han descrito Borges y Lovecraft. (Francisco Carrera, 1999: 18)

Retornando nuevamente al ámbito de lo sublime, cabe destacar cómo la categoría ha sido ejemplificada por algunos autores como el sentimiento que produce la 
visión aterradora de un naufragio a la vez que, en el último instante, nos reconocemos a salvo de la catástrofe que contemplamos. Éste fue tema recurrente a lo largo del Romanticismo, tanto en literatura como en pintura (Fig. 3).

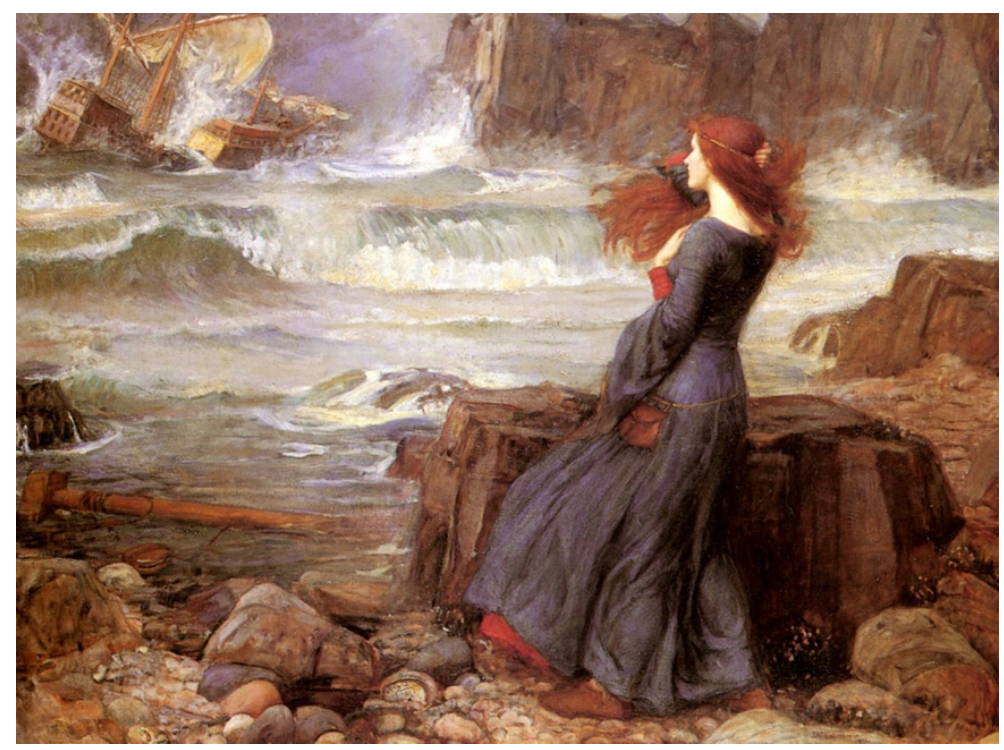

Figura 3. John William Waterhouse, Miranda - The Tempes, 1916.

En el caso de la literatura, uno de los relatos de la escritora romántica Mary Shelley, se nos presenta revelador a la hora de entender el sentimiento de lo sublime a través de la experiencia del naufragio:

Era casi de noche cuando, desde el mar y como siguiendo la estala de la mano de un hechicero, se levantó una turbia red nubosa, ocultando el azul intenso del cielo, oscureciendo y perturbando las profundidades hasta ahora plácidas. Las nubes tenían unas formas extrañas y fantásticas, y cambiaban y se mezclaban, y parecían ser manejadas por un poderoso encantamiento. Las olas alzaron sus blancas crestas; el trueno susurró, y luego rugió desde el extremo de las aguas, que adquirieron una fuerte coloración púrpura, moteadas de espuma. El lugar donde yo me erguía daba por un lado al extenso océano, y por el otro se hallaba interrumpido por un escarpado promontorio. De repente, rodeando el cabo e impulsado por el viento, surgió un navío. En vano trataron los marineros de abrirse paso hacia el mar abierto... el fuerte viento lo empujaba hacia las rocas. ¡Perecerían! ¡Todos los que iban a bordo morirían! ¡Ojalá yo estuviera entre ellos! Y por primera vez mi joven corazón recibió la idea de la muerte con júbilo. Era una visión terrible contemplar a ese barco luchando con su destino. (Shelley, 2009: 32-33)

En el relato de Mary Shelley, el protagonista llega tener ideas tan "nobles" como la de querer acompañar a los marineros, a los que observa desde el confort de la playa, en su cruzada contra el destino. "Y por primera vez mi joven corazón recibió 
la idea de la muerte con júbilo!" (Shelley, 2009: 33), llega a exclamar. Se hace patente entonces la "delicia" del terror, el sentimiento de lo sublime, que en ningún momento podrá hallarse en Lovecraft.

El protagonista lovecraftiano no se encuentra contemplando la potencia de una naturaleza que no puede dominar desde un sitio alejado y seguro. En Lovecraft el protagonista está inmerso dentro de aquella situación extrema. Siguiendo con el ejemplo del naufragio como experiencia de lo sublime, el protagonista lovecraftiano no contempla el barco colisionar con las rocas desde la playa, sino que está en el propio barco. Es uno de los hombres horrorizados ante la idea de una muerte inminente y cruel como es la de morir ahogado. El instinto de supervivencia aflora, el miedo animal se apodera de cada uno no dejando espacio a la reflexión estética. El individuo no piensa más que en huir, correr, saltar por la ventana si es necesario, como en el final del cuento Dagón con cuya cita se abría este apartado. En aquel relato de Lovecraft, escrito en 1917, el protagonista relataba en una carta cómo se topó con un mundo desconocido en una travesía marina y cómo desde su regreso a la civilización notaba que, desde su encuentro con aquel extraño mundo, algún ser venido de aquella tierra lo acechaba y perseguía esperando el momento idóneo para abalanzarse sobre él. Al notar cómo aquel ser finalmente había dado con él, antes de suicidarse deja escrito en su carta: "No me encontrará. ¡Dios mío, esa mano! ¡La ventana! ¡La ventana!”7. Es en este preciso momento, en el que el terror cósmico asoma, dónde Borges decide dar su giro argumental.

En There are more things el protagonista nota la presencia en la casa de algo que se acerca. A diferencia de lo que ocurriría en Lovecraft, el individuo toma aquí una resolución que el lector acostumbrado al relato lovecraftiano no esperaría:

Mis pies tocaban el penúltimo tramo de la escalera cuando sentí que algo ascendía por la rampa, opresivo y lento y plural. La curiosidad pudo más que el miedo y no cerré los ojos. (Borges, 2006: 68)

Los ojos que permanecen abiertos en Lovecraft no lo hacen a la curiosidad, sino al horror impronunciable de criaturas que no pueden ser descritas. Puede hacerse un paralelismo entre este final de Borges y el final de otro cuento de Lovecraft en el que el protagonista también mantuvo los ojos abiertos para escenificar el contraste entre ambos. En El morador de las tinieblas Lovecraft escribe:

El cuerpo estaba sentado muy tieso ante la mesa de su escritorio, junto a la ventana. Cuando vieron sus ojos vidriosos y desorbitados y la expresión de loco terror del semblante, los policías apartaron la vista horrorizados [...]. Blacke había seguido escribiendo frenéticamente hasta el final. Su mano derecha aún empuñaba rígidamente el lápiz, cuya punta se había debido romper en una última

\footnotetext{
${ }^{7}$ Caben destacar otros relatos, a parte del citado, como El modelo de Pickman, publicado en 1927. En dicha historia se narran las desventuras de un pintor torturado psicológicamente a causa de "algo" que nunca queda claro al lector. El artista retrata criaturas horrendas, apenas descriptibles, que llevan a su compañero, el protagonista, a plantearse si lo que contempla es fantasía o no, y si lo es, cómo es posible pintar con tanto detalle sin modelos que posaran ante el artista. Desde estos tipos de relato puede llevarse a cabo una interesante reflexión sobre la posibilidad o no de representar el horror innombrable o cósmico mediante la pintura que conectaría con algunas de las premisas aquí planteadas.
} 
contracción espasmódica [...]. He aquí sus anotaciones postreras, o al menos, lo que de ellas se ha podido descifrar: Pierdo el sentido de la distancia lo lejano está cerca y lo cercano lejos no hay luz no cristal veo la aguja la torre la ventana ruidos Roderick Usher estoy loco o me estoy volviendo ya se agita y aletea en la torre somos uno quiero salir debo salir y unificar mis fuerzas sabe dónde estoy. Soy Robert Blacke, pero veo la torre en la oscuridad. Hay un olor horrible sentidos transfigurados saltan las tablas de la torre y abre paso Iä ngai ygg Lo veo viene hacia acá viento infernal sombra titánica negras alas Yog-Sothoth, sálvame tú, ojo ardiente de tres lóbulos. (Llopis, 2012: 574)

Es más que probable que el propio Borges fuese consciente de que esta ironización del terror lovecraftniano, lejos de disipar la controversia de si le gustaron sus relatos de terror o no, generase aún más dudas acerca de su relación con la obra del norteamericano. De hecho, aún hoy se discute la valoración del argentino sobre la obra de Lovevecraft: si no le gustaba como escritor, por qué era capaz de dominar la estructura y simbología usadas por Lovecraft para sus relatos de terror. Es decir, para conocer de un modo tal la obra del norteamericano, debía haberle sido familar. ¿Había entonces leído Borges a Lovecraft aún sin gustarle? ¿a pesar de ser un mero "parodista de Poe"? Si, por el contrario, finalmente había sentido cierto aprecio o respeto por ella, por qué dar un giro en el final de su homenaje convirtiendo lo que parecía un cuento eminentemente lovecraftiano en uno borgesiano. Quizá se tratase nada más de un "juego", es decir, una manera de apropiarse de las herramientas de otro para construir algo propio. También cabe hacer un acercamiento en clave "irónica", como aquí se ha expuesto, o quizá de simple veneración y a precio ya que, al fin y al cabo, el relato de Borges comienza con una dedicatoria a la memoria de Lovecraft. Esta conexión entre Borges y Lovecraft se presenta como una relación realmente compleja que, el propio Borges, nunca dejó resuelta. Precisamente, Cristóbal Joannon ha defendido este cuento, de estructura preeminentemente lovefcraniana, como uno de los mejores ejemplos a la hora de entender un adjetivo tan ambiguo como lo es el de "borgeano", en tanto que "laberíntico, paradójico o espejeante". Según Joannon:

Ninguna de estas palabras agota lo que queremos decir cuando decimos borgeano, pero serían lados de un mismo poliedro, trazos de un mismo dibujo [...]. "There are more things" -que podríamos traducir, caprichosamente, como "Hay otras cosas"-, es, a mi modo de ver, la cristalización de ese poliedro, la consumación de ese múltiple dibujo. (Joannon, 1999: 73)

Las preguntas encuentran respuestas contradictorias en el laberinto que fue la vida de uno de los autores hispanoamericanos más famosos de su tiempo y que decidió hacer suyas algunas de las herramientas que le proporcionó Lovecraft.

\section{Referencias bibliográficas}

Aparicio Maydeu, Javier, "Del terror considerado como una de las bellas artes", prólogo a Lovecraft. El terror en la literatura. Barcelona: Austral, 2010. 
Borges, Jorge Luis. Edgar Allan Poe, en La Nación, vol. I, n. 10, 1949, p. 1. Disponible en: http://www.lamaquinadeltiempo.com/Poe/porborges.htm

- “Jorge Luis Borges: Siete noches. La pesadilla", en Ciclo de 7 conferencias organizadas el verano de 1977 en el Teatro Coliseo de Buenos Aires. Disponible en: https://www.youtube.com/watch? $=\mathrm{Cg} 8 \mathrm{vabaJEo} 8$

—El libro de los seres imaginarios. Barcelona: Bruguera, 1986.

-Introducción a la literatura norteamericana. Madrid: Alianza, 1999.

-El libro de arena. Barcelona: Debolsillo, 2011.

- El Aleph. Barcelona: De Bolsillo, 2011.

Burke, Edmund. Indagación filosófica sobre el origen de nuestras ideas acerca de lo sublime y de lo bello. Madrid: Alianza Editorial, 2014.

Francisco Carrera, Francisco José, "J. L. Borges y H. P. Lovecraft: una comparación (im)posible", Castilla. Estudios de literatura, n. 24, 1999, pp. 7-20.

Hernández, Domingo. La comedia de lo sublime. Cantabria: Quálea, 2009.

Hernández de la Fuente, David. Una mitología. Madrid: Luis Revenga, 2005.

Houllebecq, Michel. H. P. Lovecraft: Contra el mundo, contra la vida. Madrid: Siruela, 2006.

Joannon, Cristóbal. “Opresivo, lento y plural: un cuento de Borges”, Taller de letras, n. 27, 1999, pp. 73-80.

Llopis, Rafael. Los mitos de Cthulhu. Lovecraft y otros. Madrid: Alianza, 2012.

Lovecraft, Howard Phillips. El terror en la literatura. Barcelona: Austral, 2017.

Manguel, Alberto, 2006, "El horro, el horror", Letras libres, n. 12, 2006. Disponible en: http://www.letraslibres.com/revista/convivio/el-horror-el-horror

Molinuevo, José Luis. Magnifica Miseria. Murcia: Ad Hoc, 2009.

Shelley, Mary, "La Transformación", en La Transformación y otros relatos. Madrid: Ediciones El País, 2009. 